\title{
Pharmacological Actions of Myricetin in the Nervous System: A Comprehensive Review of Preclinical Studies in Animals and Cell Models
}

OPEN ACCESS

Edited by:

Morena Zusso,

University of Padua, Italy

Reviewed by:

Tuane B. Sampaio,

Federal University of Santa Maria,

Brazil

Seong Lin Teoh,

National University of Malaysia,

Malaysia

*Correspondence:

Jiashu Lu

534777178@qq.com

Specialty section:

This article was submitted to

Neuropharmacology,

a section of the journal

Frontiers in Pharmacology

Received: 18 October 2021

Accepted: 29 November 2021

Published: 16 December 2021

Citation:

Li J, Xiang H, Huang C and Lu J (2021)

Pharmacological Actions of Myricetin

in the Nervous System: A Comprehensive Review of Preclinical

Studies in Animals and Cell Models.

Front. Pharmacol. 12:797298

doi: 10.3389/fphar.2021.797298

\begin{abstract}
Jie $L^{1}{ }^{1}$, Haitao Xiang ${ }^{2}$, Chao Huang ${ }^{3}$ and Jiashu $L u^{4 *}$
${ }^{1}$ Department of Gastroenterology, The People's Hospital of Taizhou, The Fifth Affiliated Hospital of Nantong University, Taizhou, China, ${ }^{2}$ Department of Neurosurgery, Suzhou Kowloon Hospital, Shanghai Jiaotong University School of Medicine, Suzhou, China, ${ }^{3}$ Department of Pharmacology, School of Pharmacy, Nantong University, Nantong, China, ${ }^{4}$ Department of Pharmacy, The People's Hospital of Taizhou, The Fifth Affiliated Hospital of Nantong University, Taizho, China
\end{abstract}

Myricetin is a natural flavonoid extracted from a variety of plants, such as medicinal herbs, vegetables, berries, and tea leaves. A growing body of evidence has reported that myricetin supplementation display therapeutic activities in a lot of nervous system disorders, such as cerebral ischemia, Alzheimer's disease, Parkinson's disease, epilepsy, and glioblastoma. Myricetin supplementation can also protect against pathological changes and behavioral impairment induced by multiple sclerosis and chronic stress. On the basis of these pharmacological actions, myricetin could be developed as a potential drug for the prevention and/or treatment of nervous system disorders. Mechanistic studies have shown that inhibition of oxidative stress, cellular apoptosis, and neuroinflammatory response are common mechanisms for the neuroprotective actions of myricetin. Other mechanisms, including the activation of the nuclear factor E2-related factor 2 (Nrf2), extracellular signal-regulated kinase 1/2 (ERK1/2), protein kinase B (Akt), cyclic adenosine monophosphate-response element binding protein (CREB), and brain-derived neurotrophic factor (BDNF) signaling, inhibition of intracellular $\mathrm{Ca}^{2+}$ increase, inhibition of c-Jun N-terminal kinase (JNK)-p38 activation, and suppression of mutant protein aggregation, may also mediate the neuroprotective effects of myricetin. Furthermore, myricetin treatment has been shown to promote the activation of the inhibitory neurons in the hypothalamic paraventricular nucleus, which subsequently produces anti-epilepsy effects. In this review, we make a comprehensive understanding about the pharmacological effects of myricetin in the nervous system, aiming to push the development of myricetin as a novel drug for the treatment of nervous system disorders.

Keywords: myricetin, neuroinflammation, oxidative stress, brain, flavonoid

\section{INTRODUCTION}

Myricetin (Figure 1) is a natural flavonoid extracted from a variety of plants, such as vegetables, berries, and tea leaves (Gupta et al., 2020). It can produce numerous pharmacological effects, including anti-inflammation (Jang et al., 2020), anti-oxidation (Wu et al., 2016), anti-carcinogen (Xie et al., 2020), anti-diabetes (Lalitha et al., 2020), and cardio-protection (Qiu et al., 2017), and display therapeutic activities in central nervous system disorders like cerebral ischemia (Wu et al., 2016; Sun 


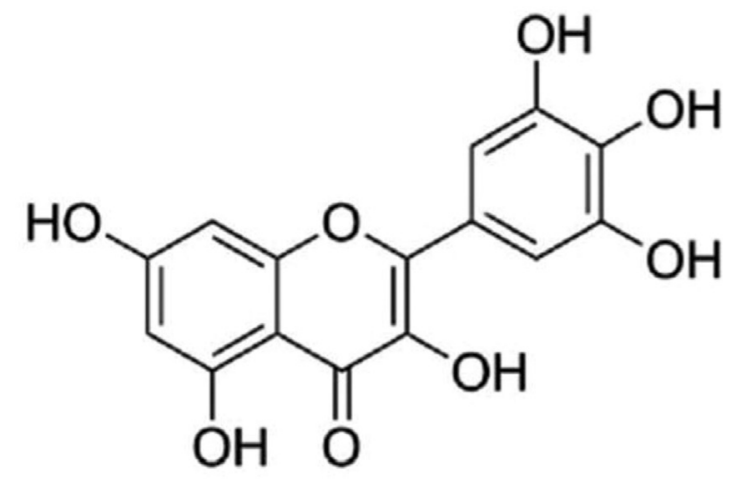

FIGURE 1 | The structure of myricetin.

et al., 2018), Parkinson's disease (Dhanraj et al., 2018), Alzheimer's disease (Liu et al., 2020), depression (Ma et al., 2015), epilepsy (Sun et al., 2019), and glioma (Li et al., 2021). Pharmacodynamic studies have revealed that myricetin has a series of deficits. Firstly, its oral bioavailability is only about 9.62 and $9.74 \%$, respectively, at 2 oral doses 50 and $100 \mathrm{mg} / \mathrm{kg}$, indicating a poor absorbing property (Dang et al., 2014). Secondly, the stability of myricetin is easily influenced by gastrointestinal environment, which is stable in simulated gastric fluids and buffer solutions with low $\mathrm{pH}$ values and experience a pseudo-first-order kinetic degradation in simulated intestinal fluids and buffer solutions with high values (Xiang et al., 2017). These deficits indicate that orally administration of myricetin can induce a state with low efficacy in brain delivery which may limit the application of myricetin in clinical practice. However, this hypothesis may be not definitely true, as the neuroprotective effects of myricetin produced by orally administration have been observed repeatedly in previous studies. For example, myricetin administration has been shown to reduce infarct brain volume in rat models of cerebral ischemia (Wu et al., 2016; Sun et al., 2018). Myricetin administration can also improve learning and memory impairment in animals who receive streptozotocin (Ramezani et al., 2016), D-galactose (Lei et al., 2012), or scopolamine (Wang et al., 2017) stimulation. In addition, myricetin administration can ameliorate the pathogenesis of Parkinson's disease in models in vitro and in vivo (Dhanraj et al., 2018; Deng et al., 2021). The discrepancy of myricetin between its low oral bioavailability and neuroprotective effects could be coordinated by a metabolism hypothesis: the orally administered myricetin could be converted into a metabolite that penetrates the blood-brain-barrier. Mechanistic studies have revealed that inhibition of neuroinflammation, oxidative stress, and cellular apoptosis (Jang et al., 2020; Boriero et al., 2021; Deng et al., 2021; Hamdi et al., 2021; Pluta et al., 2021), activation of nuclear factor E2-related factor 2 (Nrf2) (Wu et al., 2016), extracellular signal-regulated kinase 1/2 (ERK1/2) (Lei et al., 2012; Jang et al., 2020), protein kinase B (Akt) (Sun et al., 2018), and cyclic adenosine monophosphate-response element binding protein (CREB) (Lei et al., 2012), inhibition of intracellular $\mathrm{Ca}^{2+}$ increase
(Oyama et al., 1994; Chang et al., 2015), and inhibition of c-Jun N-terminal kinase (JNK) (Jang et al., 2020) or p38 (Hagenacker et al., 2010; Sun et al., 2018; Jang et al., 2020) may mediate the neuroprotective actions of myricetin. On the basis of these reports, we conclude that myricetin, dependent on its metabolites which possess neuroprotective activities, could be developed as a potential candidate for the treatment of nervous system disorders. In this review, we make a comprehensive outline for the pharmacological actions and possible mechanisms of myricetin in the nervous system by searching online literatures and databases involving in vivo animal studies and in vitro cell experiments, aiming to push the development and application of myricetin in nervous system disorder treatment.

\section{PHARMACOLOGICAL EFFECTS OF MYRICETIN IN CEREBRAL ISCHEMIA}

Cerebral ischemia is a common cerebral vascular disease which occurs in conditions like stroke (Wang et al., 2021) and hypoperfusion (Ciacciarelli et al., 2020). Oxido-nitrosative stress and neuroinflammation are two key pathological events that can mediate the pathogenesis of cerebral ischemia (Chen et al., 2020; Takeda et al., 2021). Inhibition of oxido-nitrosative stress and neuroinflammation may be beneficial for the treatment of cerebral ischemia. Orally myricetin administration once daily at the dose of 5 and $25 \mathrm{mg} / \mathrm{kg}$ (7 days) (Sun et al., 2018) or at the dose of 10 or $20 \mathrm{mg} / \mathrm{kg}$ [ $2 \mathrm{~h}$ before and every day after middle cerebral artery occlusion (MCAO)] (Wu et al., 2016) has been shown to reduce neuronal apoptosis and infarct area and improve neurological deficits in a rat model of permanent MCAO via suppressing abnormally increased pro-inflammatory cytokines, malondialdehyde (MDA), and reactive oxygen species, and abnormally decreased GSH, superoxide dismutase (SOD) activity, mitochondrial membrane potential, and adenosine triphosphate (ATP) levels in ischemic brain tissues (Sun et al., 2018; Wu et al., 2016) (Figure 2; Table 1). These effects of myricetin may be associated with the increase in Akt activity and Nrf2 nuclear translocation and the decrease in p38 or nuclear factor- $\kappa \mathrm{B}(\mathrm{NF}-\kappa \mathrm{B})$ activity (Wu et al., 2016; Sun et al., 2018) (Figure 2; Table 1). Studies in vitro have shown that myricetin pre-incubation $(10 \mathrm{nM}, 3 \mathrm{~h})$ can attenuate oxygen-glucose deprivation (OGD)-induced neuronal damage, reactive oxygen species production, and mitochondrial depolarization in $\mathrm{SH}$ SY5Y cells, with a possible mechanism involving a direct binding and inhibition of myricetin to caspase-3 (Wu et al., 2016; Figure 2 and Table 1). This indicates that reducing oxidative stress may contribute to the neuroprotective effect of myricetin in cerebral ischemia.

The $\mathrm{Ca}^{2+}$ overloading-mediated neuronal excitotoxicity is a well-known mechanism for the pathogenesis of cerebral ischemia, during which the abnormal increase in intracellular $\mathrm{Ca}^{2+}$ contributes largely to neuronal loss (Kobayashi and Mori, 1998). Although no direct evidence can support the downregulatory effect of myricetin on intracellular $\mathrm{Ca}^{2+}$ in the anti- 


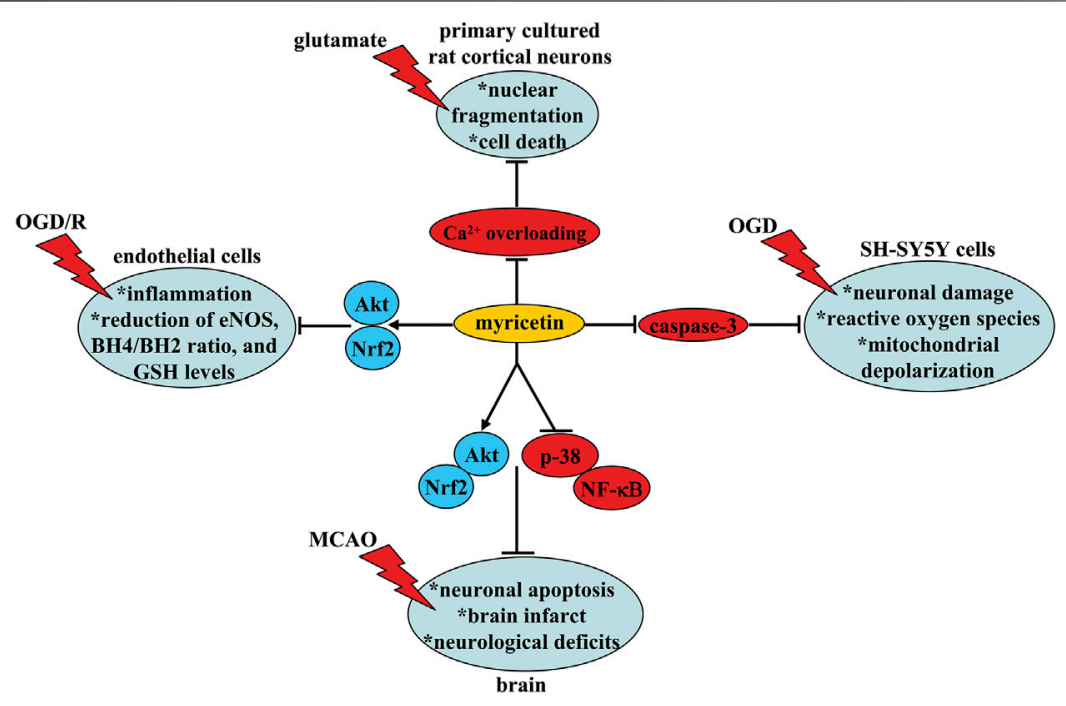

FIGURE 2 | Neuroprotective effects and possible mechanisms of myricetin in models of cerebral ischemia. Myricetin inhibits (i) OGD/R-induced inflammation, decrease in eNOS expression, phosphorylation, and activity, decrease in intracellular $\mathrm{BH} 4 / \mathrm{BH} 2$ ratio, and decrease in intracellular GSH levels in endothelial cells via stimulation of Akt and Nrf2, (ii) glutamate-induced nuclear fragmentation and cell death in primary cultured rat cortical neurons via suppression of Ca ${ }^{2+}$ overloading, and (iii) OGD-induced neuronal damage, reactive oxygen species production, and mitochondrial depolarization in SH-SY5Y cells via inhibition of caspase-3. Myricetin administration can also reduce neuronal apoptosis and infarct area and improve neurological deficits in a rat model of MCAO via increasing Akt activity, decreasing p38 and NF-кB activity, and increasing Nrf2 nuclear translocation.

TABLE 1 | Comprehensive information about the effects of myricetin in in vivo and in vitro models cerebral ischemia.

\begin{tabular}{|c|c|c|c|c|}
\hline Pharmacological effect & Object & Drug administration & Possible mechanisms & References \\
\hline${ }^{\star}$ Reduce neuronal apoptosis & Rat & ${ }^{\star} 5,25 \mathrm{mg} / \mathrm{kg}$ & $\begin{array}{l}\text { *Suppress pro-inflammatory cytokine, } \\
\text { MDA, and reactive oxygen species } \\
\text { production }\end{array}$ & Sun et al. (2018) \\
\hline${ }^{*}$ Reduce infarct area *improve neurological deficits & & *i.g & $\begin{array}{l}\text { *Increase GSH production and SOD and } \\
\text { Akt activity }\end{array}$ & \\
\hline- & & ${ }^{\star}$ Once daily, 7 days & ${ }^{\star}$ Decrease NF- $\kappa B$ activity & \\
\hline${ }^{\star}$ Reduce neuronal loss and apoptosis & Rat & ${ }^{*} 10,20 \mathrm{mg} / \mathrm{kg}$ & $\begin{array}{l}{ }^{*} \text { Reduce MDA and reactive oxygen } \\
\text { species production }\end{array}$ & Wu et al. (2016) \\
\hline${ }^{\star}$ Reduce infarct area & & *i.g & *Increase Nrf2 function & \\
\hline *Improve neurological deficits & & $\begin{array}{l}{ }^{*} 2 \mathrm{~h} \text { before and every day after } \\
\text { MCAO }\end{array}$ & *Improve mitochondrial function & \\
\hline *Improve learning and memory function & & - & - & \\
\hline $\begin{array}{l}\text { Attenuate OGD-induced neuronal damage, reactive } \\
\text { oxygen species production, and mitochondrial } \\
\text { depolarization }\end{array}$ & $\begin{array}{l}\text { SH-SY5Y } \\
\text { cells }\end{array}$ & $\begin{array}{l}{ }^{*} 10 \mathrm{nM} \\
{ }^{*} 3 \mathrm{~h} \text { before ODG exposure }\end{array}$ & *Inhibit caspase-3 activity & Wu et al. (2016) \\
\hline $\begin{array}{l}\text { Prevent glutamate-induced nuclear fragmentation and } \\
\text { cell death }\end{array}$ & $\begin{array}{l}\text { Rat cortical } \\
\text { neurons }\end{array}$ & $\begin{array}{l}{ }^{*} 0.1,0.3,1,3,10 \mu \mathrm{M} \\
{ }^{\star} 24 \mathrm{~h} \text { of pretreatment along with } \\
24 \mathrm{~h} \text { of simultaneous treatment }\end{array}$ & $\begin{array}{l}\text { Suppress } \mathrm{Ca}^{2+} \text { overloading, reactive } \\
\text { oxygen species production, and } \\
\text { caspase- } 3 \text { activation }\end{array}$ & $\begin{array}{l}\text { Shimmyo et al., } \\
2008\end{array}$ \\
\hline $\begin{array}{l}\text { Reduce 4-AP-induced } \mathrm{Ca}^{2+} \text { influx, neuronal } \\
\text { depolarization, and glutamate release }\end{array}$ & $\begin{array}{l}\text { Isolated nerve } \\
\text { terminals }\end{array}$ & $30 \mu \mathrm{M}$ co-incubation & $\begin{array}{l}\text { Block the } \mathrm{N} \text {-type and } \mathrm{P} / \mathrm{Q} \text {-type } \mathrm{Ca}^{2+} \\
\text { channel }\end{array}$ & $\begin{array}{l}\text { Chang et al. } \\
(2015)\end{array}$ \\
\hline $\begin{array}{l}{ }^{*} \text { Reduce OGD/R-induced pro-inflammatory cytokine } \\
\text { production and decrease in eNOS expression/ }\end{array}$ & HBMECs & $\begin{array}{l}{ }^{*} 10,30,60 \mu \mathrm{M} \\
{ }^{\star} \text { Pretreatment, } 24 \mathrm{~h}\end{array}$ & Activate the Akt and Nrf2 signal & $\begin{array}{l}\text { Zhang et al. } \\
\text { (2019) }\end{array}$ \\
\hline
\end{tabular}
phosphorylation/activity, $\mathrm{BH}_{4} / \mathrm{BH}_{2}$ ratio, and $\mathrm{GSH}$ levels

cerebral ischemia effect of myricetin, some in vitro studies may provide indirect evidence. For example, myricetin pretreatment $(0.1,0.3,1,3,10 \mu \mathrm{M}, 24 \mathrm{~h})$ has been shown to prevent glutamateinduced nuclear fragmentation and cell death in primary cultured rat cortical neurons by suppressing the $\mathrm{N}$-methyl-D-aspartic acid (NMDA) receptor-mediated $\mathrm{Ca}^{2+}$ overloading, reactive oxygen species production, and caspase- 3 activation (Shimmyo et al., 2008; Figure 2 and Table 1). Myricetin incubation $(30 \mu \mathrm{M})$ can also reduce $\mathrm{Ca}^{2+}$ influx, neuronal depolarization, and glutamate release in isolated nerve terminals induced by a potassium channel blocker 4-aminopyridine (4-AP) via blocking the N-type and P/Q-type $\mathrm{Ca}^{2+}$ channels (Chang et al., 2015; 


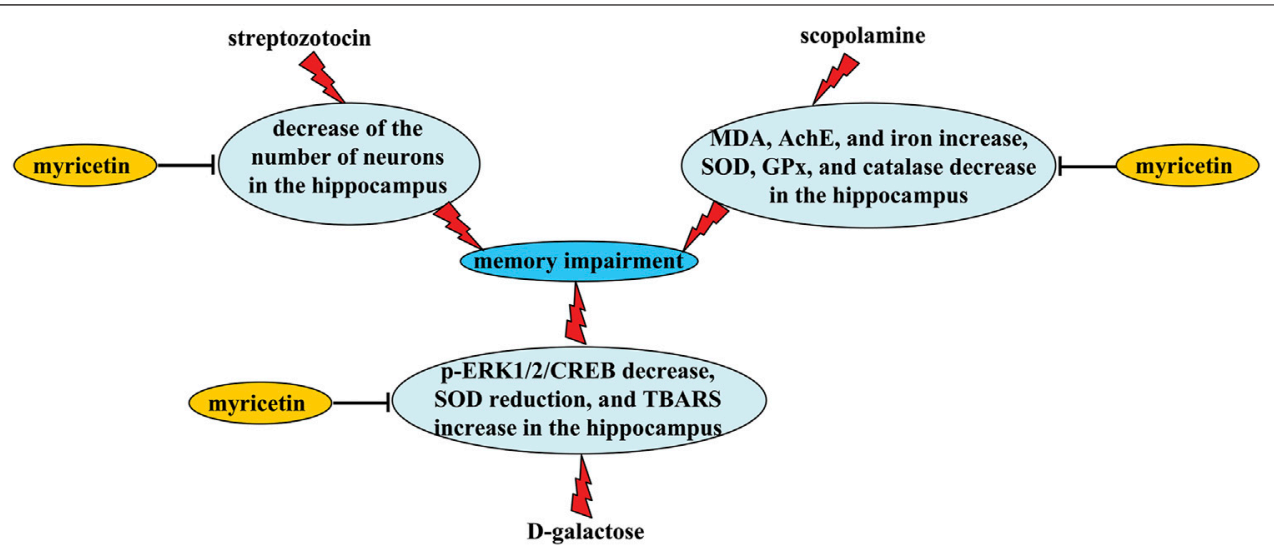

FIGURE 3 | Neuroprotective effects and possible mechanisms of myricetin in Alzheimer's disease-associated models. Myricetin administration can suppress (i) streptozotocin-induced memory impairment via inhibiting streptozotocin-induced decrease in neuronal numbers in the hippocampus, (ii) D-galactose-induced memory impairment via inhibiting scopolamine-induced increase in MDA levels and iron contents and decrease in SOD, GPx, and catalase activities in the hippocampus, and (iii) D-galactose-induced memory impairment via inhibiting D-galactose-induced decrease in the phospho-ERK1/2 and -CREB, decrease in SOD activity, and increase in TBARS levels in the hippocampus.

Figure 2 and Table 1). However, whether inhibition of $\mathrm{Ca}^{2+}$ overloading indeed contributes to the neuroprotective actions of myricetin should be ascertained in future studies.

The dysfunction of the endothelium is a known pathological event that mediates the impairment in blood-brain-barrier in cerebral ischemia (Andjelkovic et al., 2019). Methods that restore the function of the endothelium may help to ameliorate neuronal damages in cerebral ischemia. Myricetin pre-incubation (10, 30, or $60 \mu \mathrm{M}, 24 \mathrm{~h}$ ) can ameliorate OGD/R-induced production of pro-inflammatory cytokines, decrease in endothelial nitric oxide synthase (eNOS) expression/phosphorylation/activity, decrease in intracellular tetrahydrobiopterin $\left(\mathrm{BH}_{4}\right) / \mathrm{BH}_{2}$ ratio, and decrease in intracellular glutathione (GSH) levels in human brain micro-vessel endothelial cell (HBMECs) (Zhang et al., 2019; Figure 2 and Table 1), which may indicate a state of eNOS uncoupling and permeability increase. These effects of myricetin may be dependent on Akt or Nrf2, as inhibition of Akt or Nrf2, both of which could be activated by myricetin, can block the improvement effect of myricetin on eNOS activity and endothelial permeability (Zhang et al., 2019; Figure 2 and Table 1). These results uncover a possibility that improving the functions of the endothelium may contribute to the anticerebral ischemia effect of myricetin. In view of the importance of the endothelium in brain homeostasis (van Ierssel et al., 2014), researchers should further establish the causal relationship between the regulatory effect of myricetin on cerebral ischemia and endothelial cells in future studies.

\section{PHARMACOLOGICAL EFFECTS OF MYRICETIN IN ALZHEIMER'S DISEASE}

Alzheimer's disease (AD) is a common neurodegenerative disease with progressive worsening in cognition- and memory-associated neuronal functions (Rahimi, 2021). To date, no definite drugs could be available for the treatment of $\mathrm{AD}$, which is partially due to the deficiency of the understanding about the pathological mechanisms of AD. Therefore, it is urgent to search novel drugs for the treatment of $\mathrm{AD}$. Myricetin could be a drug for that purpose. Firstly, myricetin administration (5 or $10 \mathrm{mg} / \mathrm{kg}$, i. p., started 1 day before stereotactic surgery, 21 days) can suppress memory impairment in a rat model of $\mathrm{AD}$ induced by streptozotocin (Ramezani et al., 2016; Figure 3 and Table 2). Secondly, orally myricetin administration $(100 \mathrm{mg} / \mathrm{kg}$, once daily, 8 weeks) has been shown to suppress D-galactose-induced memory impairment in mice, which was indicated by the decrease in the number of platform crossings, the decrease in the time and distance spent in the target quadrant, and the increase in the time of first crossing (Lei et al., 2012; Figure 3 and Table 2). Thirdly, orally myricetin administration (25 or $50 \mathrm{mg} / \mathrm{kg}$, once daily, 6 days) can suppress scopolamine-induced decreases in platform crossings and swimming time that spent in the target quadrant in the Morris Water Maze $(M W M)$ test in mice (Wang et al., 2017; Figure 3 and Table 2).

Mechanistic studies have shown that myricetin improves learning and memory impairment in rodent models of $\mathrm{AD}$ likely through reversing streptozotocin-induced decrease in neuronal numbers in the hippocampus (Ramezani et al., 2016) or D-galactose-induced decrease in the phosphorylation levels of ERK1/2 and CREB (Lei et al., 2012; Figure 3 and Table 2), two molecules that have neuroprotective functions. In vitro studies have reported that pre- or simultaneous administration of myricetin $(0.3,1,3$ and/or $10 \mu \mathrm{M}, 48 \mathrm{~h})$ can suppress $\mathrm{A} \beta_{1-42^{-}}$ induced nuclear fragmentation and caspase- 3 activation in primary cultured cortical neurons, and reduce $A \beta_{1-40} / A \beta_{1-42}$ levels in neuronal culture media via the promotion of a-secretase (ADAM10) expression and the inhibition of $\beta$-secretase (BACE-1) activity (Shimmyo et al., 2008), suggesting that promoting neuronal survival and inhibiting $A \beta$ accumulation may mediate the anti-AD's effects of myricetin. In addition, myricetin administration has been shown to reverse D-galactose-induced decreases in SOD activity and increases in 
TABLE 2 | Comprehensive information about the effects of myricetin in animal models Alzheimer's disease.

\begin{tabular}{|c|c|c|c|c|}
\hline Pharmacological effect & Object & Drug administration & Possible mechanisms & References \\
\hline Suppress streptozotocin-induced memory impairment & Rat & $\begin{array}{l}\text { *5, } 10 \mathrm{mg} / \mathrm{kg} \\
\text { *i.p } \\
\text { *1 day before stereotactic } \\
\text { surgery, } 21 \text { days }\end{array}$ & $\begin{array}{l}{ }^{*} \text { Increase neuronal numbers in the } \\
\text { hippocampus }\end{array}$ & $\begin{array}{l}\text { Ramezani et al. } \\
\text { (2016) }\end{array}$ \\
\hline Suppress D-galactose-induced memory impairment & Mouse & $\begin{array}{l}{ }^{*} 100 \mathrm{mg} / \mathrm{kg} \\
{ }^{*} \text { i.g } \\
{ }^{*} \text { once daily, } 8 \text { weeks }\end{array}$ & $\begin{array}{l}\text { *Up-regulate } p \text {-ERK } 1 / 2 / \text { CREB } \\
\text { *Increase SOD activity } \\
\text { *Decrease TBARS levels }\end{array}$ & Lei et al. (2012) \\
\hline $\begin{array}{l}\text { Suppress scopolamine-induced decrease in platform } \\
\text { crossings and swimming time spent in the target } \\
\text { quadrant in the Morris Water Maze test }\end{array}$ & Mouse & $\begin{array}{l}{ }^{\star} 25,50 \mathrm{mg} / \mathrm{kg} \\
{ }^{*} \text { i.g } \\
{ }^{*} \text { once daily, } 6 \text { days }\end{array}$ & $\begin{array}{l}{ }^{*} \text { Reduce MDA levels and AChE activity, and } \\
\text { increase SOD, GPx, catalase activity in the } \\
\text { hippocampus }\end{array}$ & $\begin{array}{l}\text { Wang et al. } \\
\text { (2017) }\end{array}$ \\
\hline $\begin{array}{l}\text { Suppress } A \beta_{1-42} \text {-induced nuclear fragmentation and } \\
\text { caspase- } 3 \text { activation }\end{array}$ & $\begin{array}{l}\text { Cortical } \\
\text { neurons }\end{array}$ & ${ }^{\star} 0.3,1,3,10 \mu \mathrm{M}$ & ${ }^{\star}$ Promote ADAM10 expression & $\begin{array}{l}\text { Shimmyo et al., } \\
2008\end{array}$ \\
\hline Reduce $A \beta_{1-40} / A \beta_{1-42}$ levels & & $\begin{array}{l}{ }^{\star} \text { Pretreatment } 24 \mathrm{~h} \text { along with } \\
24 \mathrm{~h} \text { of simultaneous treatment }\end{array}$ & *Inhibit BACE-1 activity & \\
\hline $\begin{array}{l}\text { Reverse scopolamine-induced increase in iron } \\
\text { contents in the hippocampus }\end{array}$ & mouse & $\begin{array}{l}{ }^{*} 25,50 \mathrm{mg} / \mathrm{kg} \\
{ }^{*} \mathrm{i} . \mathrm{g} \\
{ }^{*} \text { Once daily, } 6 \text { days }\end{array}$ & $\begin{array}{c}{ }^{*} \text { Chelate intracellular } \mathrm{Fe}^{2+} \\
{ }^{*} \text { Inhibit TrR1 expression } \\
-\end{array}$ & $\begin{array}{l}\text { Wang et al. } \\
(2017)\end{array}$ \\
\hline
\end{tabular}

levels of thiobarbituric acid reactive substances (TBARS) (Lei et al., 2012; Figure 3 and Table 2), or scopolamine-induced increases in malondialdehyde $(M D A)$ levels and decreases in SOD, glutathione peroxidase (GPx), and catalase activities in the hippocampus (Wang et al., 2017; Figure 3 and Table 2), suggesting that anti-oxidation may mediate the anti-AD's effects of myricetin, at least in rodent models of $\mathrm{D}$-galactose or scopolamine stimulation.

Iron over-accumulation has been shown to be actively involved in $\mathrm{AD}$ pathogenesis. Inhibition of iron accumulation may help to ameliorate AD symptoms (Li et al., 2017; Schröder et al., 2013). Myricetin treatment (25 or $50 \mathrm{mg} / \mathrm{kg}$, once daily, 6 days) can reverse scopolamine-induced increases in iron contents in the hippocampus in mice via direct chelating of intracellular $\mathrm{Fe}^{2+}$ or inhibition of transferrin receptor 1 (TrR1) expression (Wang et al., 2017), suggesting that inhibition of iron accumulation may contribute to the neuroprotective effects of myricetin in $\mathrm{AD}$. Cholinergic hypofunction is another pathological process in $\mathrm{AD}$ (Ahmed et al., 2017). In mouse models of $\mathrm{AD}$, myricetin administration $(25$ or $50 \mathrm{mg} / \mathrm{kg}$, once daily, 6 days) can prevent scopolamine-induced increases in acetylcholinesterase (AChE) activities, thereby inducing significant increases in acetylcholine contents in the hippocampus (Wang et al., 2017; Figure 3 and Table 2), suggesting that reversing cholinergic hypofunction may be a key mechanism for the anti-AD's effects of myricetin. This hypothesis could be supported by studies in vitro: myricetin incubation $(0.016,0.063,0.25,1$, and $4 \mu \mathrm{M})$ can inhibit the activity of AChE in a dose-dependent manner in SH-SY5Y cells (Wang et al., 2017).

\section{PHARMACOLOGICAL EFFECTS OF MYRICETIN IN PARKINSON'S DISEASE}

Parkinson's disease (PD) is a neurodegenerative disease with dopaminergic neuronal degeneration in the Substantia Nigra pars compacta $(\mathrm{SNc})$ and dopamine depletion in the striatum (Mishra et al., 2019; Serra et al., 2021). Besides the use of strategies that restore a normal dopamine signaling, no effective methods could be available for PD treatment in clinic. In a previous study, lateral cerebral ventricle injection of myricetin $(0.5 \mathrm{mg} / \mathrm{ml}$, 7 days) has been shown to reverse 6-hydroxydopamine (6OHDA)-induced decreases in dopamine contents in the striatum in rats via increasing tyrosine hydroxylase expression in the substantia nigra (Ma et al., 2007; Figure 4 and Table 3). In a Drosophila model of PD, myricetin administration $(314 \mathrm{mM}, 3 \mathrm{~h}$ before rotenone exposure, 7 days) was found to suppress rotenone-induced gait disturbance, muscular dys-coordination, and memory impairment (Dhanraj et al., 2018; Figure 4 and Table 3).

One of the mechanisms that mediate the anti-PD's effects of myricetin may be associated with anti-oxidation. Firstly, in Drosophila, myricetin treatment $(314 \mathrm{mM}, 3 \mathrm{~h}$ before rotenone exposure, 7 days) was found to suppress rotenone-induced increases in TBARS levels and decreases in GSH levels (Dhanraj et al., 2018) (Figure 4). Secondly, myricetin coincubation $(50 \mu \mathrm{M})$ has been shown to attenuate 1-methyl-4phenylpyridinium ion $\left(\mathrm{MPP}^{+}\right)$-induced cell loss and nuclear condensation by restoring mitochondrial transmembrane potential and suppressing the production of reactive oxygen species in MES23.5 cells, a type of cells with similar properties as the neurons in the substantia nigra (Zhang et al., 2011; Figure 4 and Table 3). Thirdly, myricetin incubation $(50 \mu \mathrm{M}, 30 \mathrm{~min}$ before rotenone treatment) in SH-SY5Y cells prevents rotenone-induced cell loss via suppressing DNA fragmentation, lipid peroxidation, and the production of hydrogen peroxide and superoxide anion (Molina-Jiménez et al., 2004; Figure 4 and Table 3).

Besides oxido-nitrosative stress and cellular apoptosis, iron accumulation is also known to mediate the pathogenesis of PD (Raj et al., 2021); suppression of iron accumulation may be a potential strategy for the treatment of PD. Myricetin treatment (lateral cerebral ventricle injection; $0.5 \mathrm{mg} / \mathrm{ml}, 7$ days) can 


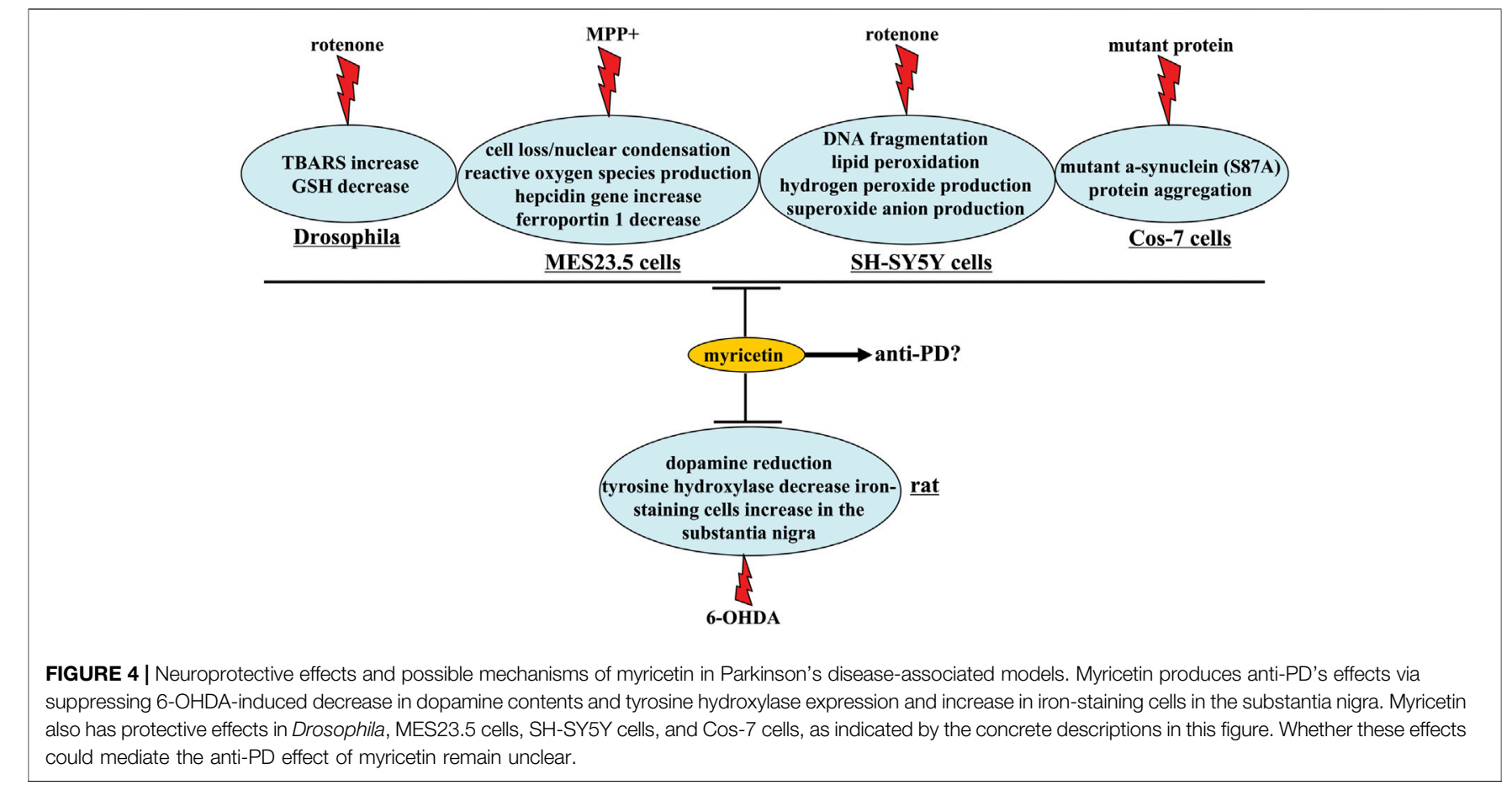

TABLE 3 | Comprehensive information about the effects of myricetin in animal models Parkinson's disease.

\begin{tabular}{|c|c|c|c|c|}
\hline Pharmacological effect & Object & Drug administration & Possible mechanisms & References \\
\hline $\begin{array}{l}\text { Reverse 6-OHDA-induced decrease in dopamine } \\
\text { contents in the striatum }\end{array}$ & Rat & $\begin{array}{l}{ }^{*} 0.5 \mathrm{mg} / \mathrm{ml} \\
\text { *lateral cerebral } \\
\text { ventricle injection } \\
{ }^{*} 7 \text { days }\end{array}$ & $\begin{array}{l}\text { Increase tyrosine hydroxylase expression and } \\
\text { reduce iron-staining cells in the substantia nigra }\end{array}$ & Ma et al. (2007) \\
\hline $\begin{array}{l}\text { Suppress rotenone-induced gait disturbance, } \\
\text { muscular dys-coordination, memory impairment, } \\
\text { dopaminergic neuronal degeneration, and dopamine } \\
\text { reduction }\end{array}$ & Drosophila & $\begin{array}{l}\text { *314 } \mathrm{mM} \\
\text { *3 } \mathrm{h} \text { before rotenone } \\
\text { exposure } \\
\text { *7 days }\end{array}$ & $\begin{array}{l}{ }^{*} \text { Reduce TBARS levels and Bax expression } \\
\text { *Increase GSH levels and Bcl-2 expression }\end{array}$ & Dhanraj et al. (2018) \\
\hline $\begin{array}{l}\text { Attenuate } \mathrm{MPP}^{+} \text {-induced cell loss and nuclear } \\
\text { condensation }\end{array}$ & $\begin{array}{l}\text { MES23.5 } \\
\text { cells }\end{array}$ & $50 \mu \mathrm{M}$ Co-treatment & $\begin{array}{l}\text { *Restore mitochondrial transmembrane potential } \\
{ }^{*} \text { Suppress reactive oxygen species production }\end{array}$ & Zhang et al. (2011) \\
\hline Prevent rotenone-induced cell loss & $\begin{array}{l}\text { SH-SY5Y } \\
\text { cells }\end{array}$ & $\begin{array}{l}{ }^{*} 50 \mu \mathrm{M} \\
{ }^{*} 30 \mathrm{~min} \text { before } \\
\text { rotenone treatment }\end{array}$ & $\begin{array}{l}\text { *Suppress DNA fragmentation, lipid peroxidation, } \\
\text { and the production of hydrogen peroxide and } \\
\text { superoxide anion }\end{array}$ & $\begin{array}{l}\text { Molina-Jiménez } \\
\text { et al. (2004) }\end{array}$ \\
\hline Alleviate rotenone-induced decreases in cell viability & $\begin{array}{l}\text { MES23.5 } \\
\text { cells }\end{array}$ & $\begin{array}{l}{ }^{*} 1 \mu \mathrm{M} \\
{ }^{\star} 24 \mathrm{~h} \text { of pretreatment } \\
- \\
-\end{array}$ & $\begin{array}{l}\text { *Suppress reactive oxygen species production } \\
\text { *Restore mitochondrial transmembrane potential } \\
\text { *Reduce hepcidin gene transcription } \\
\text { *Increase ferroportin } 1 \text { expression }\end{array}$ & Deng et al. (2021) \\
\hline $\begin{array}{l}\text { Suppress the aggregation of the mutant } \alpha \text {-synuclein } \\
\text { (S87A) protein }\end{array}$ & Cos-7 cells & $\begin{array}{l}{ }^{*} 10 \mu \mathrm{M} \\
* 48 \mathrm{~h}\end{array}$ & Activate the ubiquitin-proteasome pathway & Joshi et al. (2019) \\
\hline
\end{tabular}

prevent 6-OHDA-induced increase of iron-staining cells in the substantia nigra of rats (Ma et al., 2007), and in MES23.5 cells, myricetin pre-treatment $(1 \mu \mathrm{M}, 24 \mathrm{~h})$ has been reported to suppress rotenone-induced hepcidin gene transcription and decrease in ferroportin 1, an iron efflux transporter that can inhibit iron efflux (Deng et al., 2021; Figure 4 and Table 3), suggesting that inhibition of iron accumulation-associated pathologies in the substantia nigra may contribute to the antiPD's effects of myricetin. In addition, myricetin incubation $(10 \mu \mathrm{M}, 48 \mathrm{~h})$ has been shown to suppress the aggregation of the mutant $\alpha$-synuclein (S87A) protein in Cos-7 cells via the activation of the ubiquitin-proteasome pathway (Joshi et al., 2019; Figure 4 and Table 3). As the a-synuclein (S87A) mutant is tightly associated with PD (Oueslati et al., 2012), this finding demonstrated that inhibition of $\alpha$-synuclein (S87A) aggregation may be another mechanism for the anti-PD's effects of myricetin. In fact, inhibition of protein aggregation is a featured characteristic of myricetin, as myricetin incubation $(10 \mu \mathrm{M}$, $48 \mathrm{~h}$ ) can suppress the aggregation of the misfolded $\triangle 9$ CAT mutant protein, thermally denatured misfolded protein, 
mutant SOD-1 protein associated with Amyotrophic Lateral Sclerosis, and expanded (HDQ74) polyglutamine protein associated with Huntington's disease in Cos-7 cells (Joshi et al., 2019). Catechol O-methyltransferase (COMT) is an enzyme whose inhibition can increase the bioavailability of L-dopa (Bonifácio et al., 2007). Myricetin incubation (10, 20, or $50 \mu \mathrm{M})$ has been shown to inhibit the activity of COMT, suggesting that the previously-observed elevation of striatal dopamine levels in myricetin-treated rats is possibly mediated by the direct inhibition of myricetin on COMT activity (Zhu and Jia, 2014).

\section{PHARMACOLOGICAL EFFECTS OF MYRICETIN IN EPILEPSY}

Epilepsy is a nervous system disorder characterized by the abnormal increase in neuronal excitability (Hamed, 2020). How to calm-down the over-activated neurons is always a research topic. Orally myricetin administration (100 or $200 \mathrm{mg} / \mathrm{kg}, 26$ days, $30 \mathrm{~min}$ prior to each pentylenetetrazol injection) can reduce seizure rates in a mouse model of epilepsy induced by pentylenetetrazole likely through up-regulating the expression of Bcl-2, Bcl-xL, brain-derived neurotrophic factor (BDNF), glutamate decarboxylase 65 (GAD65), and $\gamma$-aminobutyric acid $\left(\mathrm{GABA}_{\mathrm{A}}\right)$, down-regulating the expression of caspase-3, Bad, and Bax, up-regulating the levels of GABA, and reducing glutamate contents and matrix metalloprotein-9 (MMP-9) activity in the hippocampus (Sun et al., 2019). Myricetin incubation $(5 \mu \mathrm{g} / \mathrm{ml})$ can also promote the GABAergic activity in hypothalamic paraventricular nucleus (PVN) neurons by increasing the decay time and frequency of the inhibitory currents mediated by the $\mathrm{GABA}_{\mathrm{A}}$ receptor (Zhang et al., 2012). These effects of myricetin may be mediated by the $\mathrm{Ca}^{2+}-\mathrm{Ca}^{2+} /$ calmodulin dependent protein kinase II (CaMKII) signaling, as myricetin can activate the T-and L-type $\mathrm{Ca}^{2+}$ channel and increase the levels of phospho-CaMKII (Zhang et al., 2012). Further analysis showed that the enhancing effect of myricetin on GABAergic activity was not mediated by antagonizing the $\mathrm{GABA}_{\mathrm{A}}$ receptor benzodiazepine-binding site (Zhang et al., 2012), suggesting that the action mode of myricetin on the $\mathrm{GABA}_{\mathrm{A}}$ receptor may be distinct from the most existing benzodiazepine-binding site agonists of $\mathrm{GABA}_{\mathrm{A}}$ receptors. In addition, the same dose of myricetin incubation can enhance a type of potassium currents in hypothalamic type-I PVN neurons in a $\mathrm{Ca}^{2+}$-dependent manner, and this type of currents may be the $\mathrm{Ca}^{2+}$ activated potassium current, as these currents could be activated in a relative high voltage (more positive than $-40 \mathrm{mV}$ ) and be inactivated slowly (Ma and Liu, 2012), which is in accordance with the property of the typical $\mathrm{Ca}^{2+}$-activated potassium current (Li and Ferguson, 1996).

\section{PHARMACOLOGICAL EFFECTS OF MYRICETIN IN GLIOMA}

Glioblastoma is the most common type of glioma with high proliferative activities. It can be treated by methods including chemotherapy, radiotherapy, and surgery (Cruz Da Silva et al., 2021). The current therapies are only partially useful and the median survival time of glioblastoma patients receiving the current therapies is lesser than 18 months (Otto-Meyer et al., 2020). Thus, it is urgent to search novel drugs for the treatment of glioblastoma. Myricetin may have a potential to be developed as a novel anti-tumor agent due to its remarkable anti-cancer properties. In a previous study, a sub-toxic dose of myricetin incubation $(50 \mu \mathrm{M})$ has been shown to enhance tumor necrosis factor-related apoptosis-inducing ligand (TRAIL)-induced apoptosis of glioblastoma cells by augmenting the activation of caspases-3/-7/-8/-9 (Siegelin et al., 2009). Bcl-2 and the short isoform of c-FLIP, two proteins which can inhibit TRAILtriggered cellular apoptosis, appear to mediate the sensitization effect of myricetin in glioblastoma cells, as their expression can be down-regulated by myricetin incubation $(50 \mu \mathrm{M})$, and their overexpression can abrogate the facilitation effect of myricetin on TRAIL-induced apoptosis of glioblastoma cells (Siegelin et al., 2009). In another study by Zhao et al. (2018), myricetin incubation $(\geq 20 \mu \mathrm{M})$ was found to inhibit glioblastoma cell proliferation, migration, and invasion by blocking the formation of lamellipodia, focal adhesions, membrane ruffles, and vasculogenic mimicry in a manner dependent on the suppression of Akt, c-Jun, Rho-associated protein kinase 2 (ROCK2), paxillin, and cortactin phosphorylation. In U251 human glioma cells, myricetin incubation $(5,15,30,60,120$, $240 \mu \mathrm{M}$ ) was found to alter the glioma cell shape, which is likely associated with the promotion of cellular apoptosis ( $\mathrm{Li}$ et al., 2021). Medulloblastoma is a highly metastatic disease in children. The activation of the hepatocyte growth factor (HGF) signaling is a known mechanism for the progression of medulloblastoma; its inhibition is a potential strategy for the treatment of medulloblastoma (Onvani et al., 2012). Myricetin incubation $(2.5,5,10,20 \mu \mathrm{M})$ can prevent HGF-induced phosphorylation of Met, a tyrosine kinase receptor for HGF, in a medulloblastoma cell line (DAOY), and HGF-induced formation of membrane ruffles of DAOY cells, thereby suppressing the migration of DAOY cells and tumor invasion (Labbé et al., 2009).

\section{THE OTHER PHARMACOLOGICAL EFFECTS OF MYRICETIN IN THE NERVOUS SYSTEM}

Multiple sclerosis is an autoimmune disease which can induce severe oxidative stress in the nervous system; rectifying the imbalance of oxidative stress may help to ameliorate the pathogenesis of multiple sclerosis (Tanaka and Vécsei, 2020). Orally myricetin administration ( $100 \mathrm{mg} / \mathrm{kg}$, once daily, 5 weeks) has been shown to ameliorate hyper-locomotion, sustain the balance of mice for a longer time in a high-speed rotating cylinder, reverse spatial learning and memory damage, hinder myelin reduction, and promote myelination in cuprizone-treated mice by promoting the nuclear translocation of Nrf2 and heme oxygenase-1 (HO-1) and $\mathrm{NAD}(\mathrm{P}) \mathrm{H}$ :quinone oxidoreductase 1 (NQ O 1) expression, reducing MDA levels, and increasing SOD/ catalase activities (Zhang et al., 2016). These results demonstrate 
that myricetin can ameliorate the neurological deficits in pathogenesis of multiple sclerosis via the Nrf-2-mediated antioxidative signaling, and myricetin could be developed as a novel drug for the treatment of multiple sclerosis.

Chronic stress exposure is a common pathological factor that can induce behavioral abnormalities indicating the occurrence of various psychological disorders in the modern society. Mechanisms that mediate stress-induced behavioral abnormalities are largely unknown. The dysfunctions of the endocrine system, oxidative stress, and neurotrophic factor can be used to explain the pathogenesis of stress-induced psychological disorders (Claudino et al., 2020; McEwen and Akil, 2020; Satoh, 2021). Myricetin administration (50 mg/kg, i. p., 21 days) has been shown to reduce repeated restraint stress-induced increases in immobility time in mice in the forced swimming and tail suspension test likely through reducing the plasma corticosterone levels and increasing hippocampal GSP-Px activity and BDNF expression in the hippocampus (Ma et al., 2015). Myricetin administration ( $40 \mathrm{~min}$ before each stress stimulation, $50 \mathrm{mg} / \mathrm{kg}$, i. p., 21 days) can also inhibit repeated restraint stress-induced spatial memory in mice via reducing the levels of plasma adreno-corticotrophic hormone and increasing hippocampal BDNF expression, which was indicated by the increase in the time that spent in the target quadrant in mice exposed to chronic stress in the probe trial in the Morris water maze task (Wang et al., 2016).

Neuroinflammation is a common pathological change that mediates the progression of nervous system disorders (Meyer et al., 2020; Piancone et al., 2021). Inhibition of neuroinflammation is a potential strategy for the treatment of nervous system disorders. Myricetin incubation (50 or $100 \mu \mathrm{M})$ has been shown to skew the hypoxia-triggered neuroinflammatory response towards an anti-inflammatory $\mathrm{M} 2$ phenotype in BV-2 microglia, thereby protecting the SHSY5Y cells from death induced by conditioned media from hypoxia-stimulated microglia (Boriero et al., 2021). Mechanistic studies have shown that myricetin incubation can reduce the phospho-signal transducer and activator of transcription 1 (STAT1) via a direct interaction with STAT1 protein (Boriero et al., 2021). This finding is line with a fact that STAT1 is a pivotal factor that regulates the transition of microglia towards a pro-inflammatory M1 phenotype under hypoxia in a phosphorylation-dependent manner (Butturini et al., 2019). Myricetin incubation (10 and $25 \mu \mathrm{M}$ ) can also down-regulate lipopolysaccharide (LPS)-induced increase in interleukin-1 $\beta$ (IL-1 $\beta$ ), tumor necrosis factor- $\alpha$ (TNF- $\alpha$ ), inducible nitric oxide synthase (iNOS), cyclooxygenase-2 (COX-2), and prostaglandin E2 (PGE2) levels in BV-2 microglia via inhibiting JNK and p38 phosphorylation (Jang et al., 2020), which could be evidenced by a direct inhibition of LPS-induced increase in microglial numbers in the hippocampus and prefrontal cortex (50 and $100 \mathrm{mg} / \mathrm{kg}$, i. p., once daily, 7 days) (Jang et al., 2020).

\section{CONCLUSION}

In this review, we outlined the pharmacological effects of myricetin in the nervous system. Myricetin can produce preventive and therapeutic effects in nervous system disorders through antioxidation (Wu et al., 2016), anti-proliferation (Siegelin et al., 2009; Zhao et al., 2018; Li et al., 2021), and antineuroinflammation (Jang et al., 2020; Boriero et al., 2021). The activation of the Nrf2 (Wu et al., 2016), ERK1/2 (Wang et al., 2017; Jang et al., 2020), Akt (Sun et al., 2018), CREB (Lei et al., 2012), and BDNF (Sun et al., 2019), the inhibition of intracellular $\mathrm{Ca}^{2+}$ increase and JNK-p38 activation (Oyama et al., 1994; Hagenacker et al., 2010; Chang et al., 2015; Sun et al., 2018; Jang et al., 2020), and the suppression of mutant protein aggregation (Joshi et al., 2019) and PVN neuronal activity (Ma and Liu, 2012; Zhang et al., 2012) may also mediate the neuroprotective effects of myricetin in the nervous system. However, no exact causal relationship between myricetin and its neuroprotective effects has been established. If we want to develop myricetin as a novel drug for the treatment of nervous system disorders, we should clarify the common pathway that mediates the neuroprotective effects of myricetin. We should also notice the pharmacodynamic deficits of myricetin which may restrict its application in daily-life and clinical practice, and develop novel strategies to improve the oral bioavailability of myricetin and increase the stability of myricetin in gastric fluids. These endeavors appear to be very important, as although myricetin is not being applied for the treatment of nervous system disorders, some clinical studies have revealed promising potentials for its use in clinic. For example, Emulin ${ }^{\mathrm{TM}}$ which contains myricetin has been shown to reduce blood glucose increase in type 2 diabetic patients (Ahrens and Thompson, 2013). In a 4-weeks randomized placebocontrolled clinical trial, the Blueberin which contains $50 \mathrm{mg}$ myricetin was found to reduce fasting plasma glucose and serum C-reactive proteins levels (Abidov et al., 2006). Some other studies had reported that myricetin intake is associated with lower cancer risk in humans (Knekt et al., 2002; Tang et al., 2009). Since inflammation, diabetes, and cancer are highly correlated with nervous system disorders, these previously-reported clinical studies provide indirect evidence for the development of clinical trials for myricetin in nervous system disorder treatment.

\section{AUTHOR CONTRIBUTIONS}

JL, HX, CH, and JL wrote the paper. All authors contributed to the article and approved the submitted version.

\section{ACKNOWLEDGMENTS}

The Scientific Research Project of the People's Hospital of Taizhou (ZL201950). 


\section{REFERENCES}

Abidov, M., Ramazanov, A., Jimenez Del Rio, M., and Chkhikvishvili, I. (2006). Effect of Blueberin on Fasting Glucose, C-Reactive Protein and Plasma Aminotransferases, in Female Volunteers with Diabetes Type 2: DoubleBlind, Placebo Controlled Clinical Study. Georgian Med. News 141, 66-72. doi:10.1007/s10517-006-0167-3

Ahmed, T., Zahid, S., Mahboob, A., and Farhat, S. M. (2017). Cholinergic System and Post-translational Modifications: An Insight on the Role in Alzheimer's Disease. Curr. Neuropharmacol. 15 (4), 480-494. doi:10.2174/ 1570159X14666160325121145

Ahrens, M. J., and Thompson, D. L. (2013). Effect of Emulin on Blood Glucose in Type 2 Diabetics. J. Med. Food 16 (3), 211-215. doi:10.1089/jmf.2012.0069

Andjelkovic, A. V., Xiang, J., Stamatovic, S. M., Hua, Y., Xi, G., Wang, M. M., et al. (2019). Endothelial Targets in Stroke: Translating Animal Models to Human. Arterioscler. Thromb. Vasc. Biol. 39 (11), 2240-2247. doi:10.1161/ ATVBAHA.119.312816

Bonifácio, M. J., Palma, P. N., Almeida, L., and Soares-da-Silva, P. (2007). Catechol-O-methyltransferase and its Inhibitors in Parkinson's Disease. CNS Drug Rev. 13 (3), 352-379. doi:10.1111/j.1527-3458.2007.00020.x

Boriero, D., Carcereri de Prati, A., Antonini, L., Ragno, R., Sohji, K., and Mariotto, S. (2021). The Anti-STAT1 Polyphenol Myricetin Inhibits M1 Microglia Activation and Counteracts Neuronal Death. FEBS J. 288 (7), 2347-2359. doi:10.1111/febs.15577

Butturini, E., Boriero, D., Carcereri de Prati, A., and Mariotto, S. (2019). STAT1 Drives M1 Microglia Activation and Neuroinflammation under Hypoxia. Arch. Biochem. Biophys. 669, 22-30. doi:10.1016/j.abb.2019.05.011

Chang, Y., Chang, C. Y., Wang, S. J., and Huang, S. K. (2015). Myricetin Inhibits the Release of Glutamate in Rat Cerebrocortical Nerve Terminals. J. Med. Food 18 (5), 516-523. doi:10.1089/jmf.2014.3219

Chen, S., Chen, H., Du, Q., and Shen, J. (2020). Targeting Myeloperoxidase (MPO) Mediated Oxidative Stress and Inflammation for Reducing Brain Ischemia Injury: Potential Application of Natural Compounds. Front. Physiol. 11, 433. doi:10.3389/fphys.2020.00433

Ciacciarelli, A., Sette, G., Giubilei, F., and Orzi, F. (2020). Chronic Cerebral Hypoperfusion: An Undefined, Relevant Entity. J. Clin. Neurosci. 73, 8-12. doi:10.1016/j.jocn.2020.01.026

Claudino, F. C. A., Gonçalves, L., Schuch, F. B., Martins, H. R. S., and da Rocha, N. S. (2020). The Effects of Individual Psychotherapy in BDNF Levels of Patients with Mental Disorders: A Systematic Review. Front. Psychiatry 11, 445. doi:10.3389/fpsyt.2020.00445

Cruz Da Silva, E., Mercier, M. C., Etienne-Selloum, N., Dontenwill, M., and Choulier, L. (2021). A Systematic Review of Glioblastoma-Targeted Therapies in Phases II, III, IV Clinical Trials. Cancers (Basel) 13 (8), 1795. doi:10.3390/cancers 13081795

Dang, Y., Lin, G., Xie, Y., Duan, J., Ma, P., Li, G., et al. (2014). Quantitative Determination of Myricetin in Rat Plasma by Ultra Performance Liquid Chromatography Tandem Mass Spectrometry and its Absolute Bioavailability. Drug Res. (Stuttg) 64 (10), 516-522. doi:10.1055/s-0033-1363220

Deng, H., Liu, S., Pan, D., Jia, Y., and Ma, Z. G. (2021). Myricetin Reduces Cytotoxicity by Suppressing Hepcidin Expression in MES23.5 Cells. Neural Regen. Res. 16 (6), 1105-1110. doi:10.4103/1673-5374.300461

Dhanraj, V., Karuppaiah, J., Balakrishnan, R., and Elangovan, N. (2018). Myricetin Attenuates Neurodegeneration and Cognitive Impairment in Parkinsonism. Front. Biosci. (Elite Ed. 10, 481-494. doi:10.2741/E835

Gupta, G., Siddiqui, M. A., Khan, M. M., Ajmal, M., Ahsan, R., Rahaman, M. A., et al. (2020). Current Pharmacological Trends on Myricetin. Drug Res. (Stuttg) 70 (10), 448-454. doi:10.1055/a-1224-3625

Hagenacker, T., Hillebrand, I., Büsselberg, D., and Schäfers, M. (2010). Myricetin Reduces Voltage Activated Potassium Channel Currents in DRG Neurons by a P38 Dependent Mechanism. Brain Res. Bull. 83 (5), 292-296. doi:10.1016/ j.brainresbull.2010.07.010

Hamdi, H., Abid-Essefi, S., and Eyer, J. (2021). Neuroprotective Effects of Myricetin on Epoxiconazole-Induced Toxicity in F98 Cells. Free Radic. Biol. Med. 164, 154-163. doi:10.1016/j.freeradbiomed.2020.12.451

Hamed, S. A. (2020). Cortical Excitability in Epilepsy and the Impact of Antiepileptic Drugs: Transcranial Magnetic Stimulation Applications.
Expert Rev. Neurother. 20 (7), 707-723. doi:10.1080/ 14737175.2020.1780122

Jang, J. H., Lee, S. H., Jung, K., Yoo, H., and Park, G. (2020). Inhibitory Effects of Myricetin on Lipopolysaccharide-Induced Neuroinflammation. Brain Sci. 10 (1), 32. doi:10.3390/brainsci10010032

Joshi, V., Mishra, R., Upadhyay, A., Amanullah, A., Poluri, K. M., Singh, S., et al. (2019). Polyphenolic Flavonoid (Myricetin) Upregulated Proteasomal Degradation Mechanisms: Eliminates Neurodegenerative Proteins Aggregation. J. Cell. Physiol. 234 (11), 20900-20914. doi:10.1002/jcp.28695

Knekt, P., Kumpulainen, J., Järvinen, R., Rissanen, H., Heliövaara, M., Reunanen, A., et al. (2002). Flavonoid Intake and Risk of Chronic Diseases. Am. J. Clin. Nutr. 76 (3), 560-568. doi:10.1093/ajcn/76.3.560

Kobayashi, T., and Mori, Y. (1998). Ca2+ Channel Antagonists and Neuroprotection from Cerebral Ischemia. Eur. J. Pharmacol. 363 (1), 1-15. doi:10.1016/s0014-2999(98)00774-2

Labbé, D., Provençal, M., Lamy, S., Boivin, D., Gingras, D., and Béliveau, R. (2009). The Flavonols Quercetin, Kaempferol, and Myricetin Inhibit Hepatocyte Growth Factor-Induced Medulloblastoma Cell Migration. J. Nutr. 139 (4), 646-652. doi:10.3945/jn.108.102616

Lalitha, N., Sadashivaiah, B., Ramaprasad, T. R., and Singh, S. A. (2020). Antihyperglycemic Activity of Myricetin, through Inhibition of DPP-4 and Enhanced GLP-1 Levels, Is Attenuated by Co-ingestion with Lectin-Rich Protein. PLoS One 15 (4), e0231543. doi:10.1371/journal.pone.0231543

Lei, Y., Chen, J., Zhang, W., Fu, W., Wu, G., Wei, H., et al. (2012). In Vivo investigation on the Potential of Galangin, Kaempferol and Myricetin for protection of D-Galactose-Induced Cognitive Impairment. Food Chem. 135 (4), 2702-2707. doi:10.1016/j.foodchem.2012.07.043

Li, H. G., Chen, J. X., Xiong, J. H., and Zhu, J. W. (2021). Myricetin Exhibits Antiglioma Potential by Inducing Mitochondrial-Mediated Apoptosis, Cell Cycle Arrest, Inhibition of Cell Migration and ROS Generation. J. BUON. 26 (1), 295.

Li, Y., Jiao, Q., Xu, H., Du, X., Shi, L., Jia, F., et al. (2017). Biometal Dyshomeostasis and Toxic Metal Accumulations in the Development of Alzheimer's Disease. Front. Mol. Neurosci. 10, 339. doi:10.3389/fnmol.2017.00339

Li, Z., and Ferguson, A. V. (1996). Electrophysiological Properties of Paraventricular Magnocellular Neurons in Rat Brain Slices: Modulation of IA by Angiotensin II Neuroscience 71 (1), 133-145. doi:10.1016/0306-4522(95)00434-3

Liu, M., Guo, H., Li, Z., Zhang, C., Zhang, X., Cui, Q., et al. (2020). Molecular Level Insight into the Benefit of Myricetin and Dihydromyricetin Uptake in Patients with Alzheimer's Diseases. Front. Aging Neurosci. 12, 601603. doi:10.3389/ fnagi.2020.601603

Ma, Z., and Liu, T. (2012). Myricetin Facilitates Potassium Currents and Inhibits Neuronal Activity of PVN Neurons. Neurochem. Res. 37 (7), 1450-1456. doi:10.1007/s11064-012-0732-2

Ma, Z., Wang, G., Cui, L., and Wang, Q. (2015). Myricetin Attenuates Depressantlike Behavior in Mice Subjected to Repeated Restraint Stress. Int. J. Mol. Sci. 16 (12), 28377-28385. doi:10.3390/ijms161226102

Ma, Z. G., Wang, J., Jiang, H., Liu, T. W., and Xie, J. X. (2007). Myricetin Reduces 6 Hydroxydopamine-Induced Dopamine Neuron Degeneration in Rats. Neuroreport 18 (11), 1181-1185. doi:10.1097/WNR.0b013e32821c51fe

McEwen, B. S., and Akil, H. (2020). Revisiting the Stress Concept: Implications for Affective Disorders. J. Neurosci. 40 (1), 12-21. doi:10.1523/JNEUROSCI.0733-19.2019

Meyer, J. H., Cervenka, S., Kim, M. J., Kreisl, W. C., Henter, I. D., and Innis, R. B. (2020). Neuroinflammation in Psychiatric Disorders: PET Imaging and Promising New Targets. Lancet Psychiatry 7 (12), 1064-1074. doi:10.1016/ S2215-0366(20)30255-8

Mishra, A., Singh, S., Tiwari, V., Chaturvedi, S., Wahajuddin, M., and Shukla, S. (2019). Dopamine Receptor Activation Mitigates Mitochondrial Dysfunction and Oxidative Stress to Enhance Dopaminergic Neurogenesis in 6-OHDA Lesioned Rats: A Role of Wnt Signalling. Neurochem. Int. 129, 104463. doi:10.1016/j.neuint.2019.104463

Molina-Jiménez, M. F., Sánchez-Reus, M. I., Andres, D., Cascales, M., and Benedi, J. (2004). Neuroprotective Effect of Fraxetin and Myricetin against RotenoneInduced Apoptosis in Neuroblastoma Cells. Brain Res. 1009 (1-2), 9-16. doi:10.1016/j.brainres.2004.02.065

Onvani, S., Terakawa, Y., Smith, C., Northcott, P., Taylor, M., and Rutka, J. (2012). Molecular Genetic Analysis of the Hepatocyte Growth Factor/MET Signaling Pathway in Pediatric Medulloblastoma. Genes Chromosomes Cancer 51 (7), 675-688. doi:10.1002/gcc.21954 
Otto-Meyer, S., DeFaccio, R., Dussold, C., Ladomersky, E., Zhai, L., Lauing, K. L., et al. (2020). A Retrospective Survival Analysis of Glioblastoma Patients Treated with Selective Serotonin Reuptake Inhibitors. Brain Behav. Immun. Health 2, 100025. doi:10.1016/j.bbih.2019.100025

Oueslati, A., Paleologou, K. E., Schneider, B. L., Aebischer, P., and Lashuel, H. A. (2012). Mimicking Phosphorylation at Serine 87 Inhibits the Aggregation of Human $\alpha$-synuclein and Protects against its Toxicity in a Rat Model of Parkinson's Disease. J. Neurosci. 32 (5), 1536-1544. doi:10.1523/ JNEUROSCI.3784-11.2012

Oyama, Y., Fuchs, P. A., Katayama, N., and Noda, K. (1994). Myricetin and Quercetin, the Flavonoid Constituents of Ginkgo Biloba Extract, Greatly Reduce Oxidative Metabolism in Both Resting and $\mathrm{Ca}(2+)$-Loaded Brain Neurons. Brain Res. 635 (1-2), 125-129. doi:10.1016/0006-8993(94)91431-1

Piancone, F., La Rosa, F., Marventano, I., Saresella, M., and Clerici, M. (2021). The Role of the Inflammasome in Neurodegenerative Diseases. Molecules 26 (4), 953. doi:10.3390/molecules26040953

Pluta, R., Januszewski, S., and Czuczwar, S. J. (2021). Myricetin as a Promising Molecule for the Treatment of Post-Ischemic Brain Neurodegeneration. Nutrients 13 (2), 342. doi:10.3390/nu13020342

Qiu, Y., Cong, N., Liang, M., Wang, Y., and Wang, J. (2017). Systems Pharmacology Dissection of the Protective Effect of Myricetin against Acute Ischemia/Reperfusion-Induced Myocardial Injury in Isolated Rat Heart. Cardiovasc. Toxicol. 17 (3), 277-286. doi:10.1007/s12012-016-9382-y

Rahimi, F. (2021). Alzheimer Disease: Controversies in Basic Science Research, Different Theories, and Reasons for Failed Trials. Biomedicines 9 (3), 254. doi:10.3390/biomedicines 9030254

Raj, K., Kaur, P., Gupta, G. D., and Singh, S. (2021). Metals Associated Neurodegeneration in Parkinson's Disease: Insight to Physiological, Pathological Mechanisms and Management. Neurosci. Lett. 753, 135873. doi:10.1016/j.neulet.2021.135873

Ramezani, M., Darbandi, N., Khodagholi, F., and Hashemi, A. (2016). Myricetin Protects Hippocampal CA3 Pyramidal Neurons and Improves Learning and Memory Impairments in Rats with Alzheimer's Disease. Neural Regen. Res. 11 (12), 1976-1980. doi:10.4103/1673-5374.197141

Satoh, Y. (2021). The Potential of Hydrogen for Improving Mental Disorders. Curr. Pharm. Des. 27 (5), 695-702. doi:10.2174/1381612826666201113095938

Schröder, N., Figueiredo, L. S., and de Lima, M. N. (2013). Role of Brain Iron Accumulation in Cognitive Dysfunction: Evidence from Animal Models and Human Studies. J. Alzheimers Dis. 34 (4), 797-812. doi:10.3233/JAD-121996

Serra, M., Pinna, A., Costa, G., Usiello, A., Pasqualetti, M., Avallone, L., et al. (2021). Involvement of the Protein Ras Homolog Enriched in the Striatum, Rhes, in Dopaminergic Neurons' Degeneration: Link to Parkinson's Disease. Int. J. Mol. Sci. 22 (10), 5326. doi:10.3390/ijms22105326

Shimmyo, Y., Kihara, T., Akaike, A., Niidome, T., and Sugimoto, H. (2008). Multifunction of Myricetin on A Beta: Neuroprotection via a Conformational Change of A Beta and Reduction of A Beta via the Interference of Secretases. J. Neurosci. Res. 86 (2), 368-377. doi:10.1002/jnr.21476

Shimmyo, Y., Kihara, T., Akaike, A., Niidome, T., and Sugimoto, H. (2008). Three Distinct Neuroprotective Functions of Myricetin against GlutamateInduced Neuronal Cell Death: Involvement of Direct Inhibition of Caspase-3. J. Neurosci. Res. 86 (8), 1836-1845. doi:10.1002/jnr.21629

Siegelin, M. D., Gaiser, T., Habel, A., and Siegelin, Y. (2009). Myricetin Sensitizes Malignant Glioma Cells to TRAIL-Mediated Apoptosis by Down-Regulation of the Short Isoform of FLIP and Bcl-2. Cancer Lett. 283 (2), 230-238. doi:10.1016/j.canlet.2009.04.002

Sun, L., Xu, P., Fu, T., Huang, X., Song, J., Chen, M., et al. (2018). Myricetin against Ischemic Cerebral Injury in Rat Middle Cerebral Artery Occlusion Model. Mol. Med. Rep. 17 (2), 3274-3280. doi:10.3892/mmr.2017.8212

Sun, Z. Q., Meng, F. H., Tu, L. X., and Sun, L. (2019). Myricetin Attenuates the Severity of Seizures and Neuroapoptosis in Pentylenetetrazole Kindled Mice by Regulating the of BDNF-TrkB Signaling Pathway and Modulating Matrix Metalloproteinase-9 and GABAA. Exp. Ther. Med. 17 (4), 3083-3091. doi:10.3892/etm.2019.7282

Takeda, H., Yamaguchi, T., Yano, H., and Tanaka, J. (2021). Microglial Metabolic Disturbances and Neuroinflammation in Cerebral Infarction. J. Pharmacol. Sci. 145 (1), 130-139. doi:10.1016/j.jphs.2020.11.007

Tanaka, M., and Vécsei, L. (2020). Monitoring the Redox Status in Multiple Sclerosis. Biomedicines 8 (10), 406. doi:10.3390/biomedicines8100406
Tang, N. P., Zhou, B., Wang, B., Yu, R. B., and Ma, J. (2009). Flavonoids Intake and Risk of Lung Cancer: a Meta-Analysis. Jpn. J. Clin. Oncol. 39 (6), 352-359. doi:10.1093/jjco/hyp028

van Ierssel, S. H., Jorens, P. G., Van Craenenbroeck, E. M., and Conraads, V. M. (2014). The Endothelium, a Protagonist in the Pathophysiology of Critical Illness: Focus on Cellular Markers. Biomed. Res. Int. 2014, 985813. doi:10.1155/2014/985813

Wang, B., Zhong, Y., Gao, C., and Li, J. (2017). Myricetin Ameliorates Scopolamine-Induced Memory Impairment in Mice via Inhibiting Acetylcholinesterase and Down-Regulating Brain Iron. Biochem. Biophys. Res. Commun. 490 (2), 336-342. doi:10.1016/j.bbrc.2017.06.045

Wang, Q. M., Wang, G. L., and Ma, Z. G. (2016). Protective Effects of Myricetin on Chronic Stress-Induced Cognitive Deficits. Neuroreport 27 (9), 652-658. doi:10.1097/WNR.0000000000000591

Wang, X., Fang, Y., Huang, Q., Xu, P., Lenahan, C., Lu, J., et al. (2021). An Updated Review of Autophagy in Ischemic Stroke: From Mechanisms to Therapies. Exp. Neurol. 340, 113684. doi:10.1016/j.expneurol.2021.113684

Wu, S., Yue, Y., Peng, A., Zhang, L., Xiang, J., Cao, X., et al. (2016). Myricetin Ameliorates Brain Injury and Neurological Deficits via Nrf2 Activation after Experimental Stroke in Middle-Aged Rats. Food Funct. 7 (6), 2624-2634. doi:10.1039/c6fo00419a

Xiang, D., Wang, C. G., Wang, W. Q., Shi, C. Y., Xiong, W., Wang, M. D., et al. (2017). Gastrointestinal Stability of Dihydromyricetin, Myricetin, and Myricitrin: an In Vitro Investigation. Int. J. Food Sci. Nutr. 68 (6), 704-711. doi:10.1080/09637486.2016.1276518

Xie, Y., Wang, Y., Xiang, W., Wang, Q., and Cao, Y. (2020). Molecular Mechanisms of the Action of Myricetin in Cancer. Mini. Rev. Med. Chem. 20 (2), 123-133. doi:10.2174/1389557519666191018112756

Zhang, K., Ma, Z., Wang, J., Xie, A., and Xie, J. (2011). Myricetin Attenuated MPP(+)-induced Cytotoxicity by Anti-oxidation and Inhibition of MKK4 and JNK Activation in MES23.5 Cells. Neuropharmacology 61 (1-2), 329-335. doi:10.1016/j.neuropharm.2011.04.021

Zhang, Q., Li, Z., Wu, S., Li, X., Sang, Y., Li, J., et al. (2016). Myricetin Alleviates Cuprizone-Induced Behavioral Dysfunction and Demyelination in Mice by Nrf2 Pathway. Food Funct. 7 (10), 4332-4342. doi:10.1039/c6fo00825a

Zhang, S., Hu, X., Guo, S., Shi, L., He, Q., Zhang, P., et al. (2019). Myricetin Ameliorated Ischemia/reperfusion-Induced Brain Endothelial Permeability by Improvement of eNOS Uncoupling and Activation eNOS/NO. J. Pharmacol. Sci. 140 (1), 62-72. doi:10.1016/j.jphs.2019.04.009

Zhang, X. H., Ma, Z. G., Rowlands, D. K., Gou, Y. L., Fok, K. L., Wong, H. Y., et al. (2012). Flavonoid Myricetin Modulates GABA(A) Receptor Activity through Activation of $\mathrm{Ca}(2+)$ Channels and CaMK-II Pathway. Evid. Based Complement. Alternat. Med. 2012, 758097. doi:10.1155/2012/758097

Zhao, H. F., Wang, G., Wu, C. P., Zhou, X. M., Wang, J., Chen, Z. P., et al. (2018). A Multi-Targeted Natural Flavonoid Myricetin Suppresses Lamellipodia and Focal Adhesions Formation and Impedes Glioblastoma Cell Invasiveness and Abnormal Motility. CNS Neurol. Disord. Drug Targets 17 (7), 557-567. doi:10.2174/1871527317666180611090006

Zhu, X., and Jia, Y. H. (2014). Inhibition of Catechol-O-Methyltransferase (COMT) by Myricetin, Dihydromyricetin, and Myricitrin. Pharmazie 69 (3), 183-186.

Conflict of Interest: The authors declare that the research was conducted in the absence of any commercial or financial relationships that could be construed as a potential conflict of interest.

Publisher's Note: All claims expressed in this article are solely those of the authors and do not necessarily represent those of their affiliated organizations, or those of the publisher, the editors and the reviewers. Any product that may be evaluated in this article, or claim that may be made by its manufacturer, is not guaranteed or endorsed by the publisher.

Copyright $\odot 2021 \mathrm{Li}$, Xiang, Huang and Lu. This is an open-access article distributed under the terms of the Creative Commons Attribution License (CC BY). The use, distribution or reproduction in other forums is permitted, provided the original author(s) and the copyright owner(s) are credited and that the original publication in this journal is cited, in accordance with accepted academic practice. No use, distribution or reproduction is permitted which does not comply with these terms. 